\title{
LA VACUNACIÓN: ESTRATEGIA FUNDAMENTAL EN LA ELIMINACIÓN DE LA VIRUELA EN CUBA (1804-1923)
}

\author{
Enrique Beldarraín Chaple \\ Universidad Médica de La Habana \\ Email: ebch@infomed.sld.cu \\ ORCID iD: http://orcid.org/0000-0003-4448-8661
}

Recibido: 6 febrero 2018; Aceptado: 23 septiembre 2019

Cómo citar este artículo/Citation: Beldarraín Chaple, Enrique (2020), "La vacunación: estrategia fundamental en la eliminación de la viruela en Cuba (1804-1923)", Asclepio 72 (1):p293. https://doi.org/10.3989/asclepio.2020.02.

RESUMEN: Las epidemias de viruela azotaron a Cuba desde 1522, produciendo elevada morbilidad y mortalidad. En 1804, se inició la estrategia de vacunación contra esta enfermedad que, con distintos avatares y fases en su desarrollo, tuvo como figura central a Tomas Romay. El objetivo del trabajo fue analizar los resultados de la estrategia de vacunación llevada a cabo en la eliminación de la viruela en Cuba y como se transformaron las instituciones en relación a los avances y producción de la vacuna en función del contexto científico, social y político del periodo estudiado. Las fuentes primarias utilizadas han sido diversas: fuentes de tipo epidemiológico y estadístico, documentos relacionados con los organismos puestos en marcha para la propagación y producción de la vacuna, informes institucionales y periodismo científico local. El trabajo reconstruye el papel jugado por la Junta Central de la Vacuna (1804), para planificar, ejecutar y expandir esta estrategia en el territorio, el Instituto de Vacunación Animal (1873) y el Centro General de la Vacuna (1883) en la producción de la misma. En el siglo XX, se convirtió en obligatoria por ley y junto a las estrictas medidas de aislamiento tomadas sobre los casos y los controles de focos, llevaron a la eliminación de la enfermedad a partir de 1923.

PALABRAS CLAVE: Viruela; sanidad; vacunación; historia; Tomas Romay; Cuba; siglos XIX y XX.

\section{VACCINATION: FUNDAMENTAL STRATEGY IN THE ELIMINATION OF SMALLPOX IN CUBA (1804-1923)}

ABSTRACT: The epidemics of smallpox lashed Cuba since 1522, producing high morbidity and mortality which with different ups and downs in its development, had as central figure Tomas Romay. The main aim of this paper is to analyze the results of the vaccination strategy performed in Cuba for the elimination of smallpox in Cuba and how the institutions were transformed in relation to the advances and production of the vaccine. The primary sources used have been diverse: epidemiological and statistical sources, documents related to organisms set up for to the spread and production of the vaccine, institutional reports and local scientific journalism. The work reconstructs the role played by the Central Vaccine Board (1804) emerged to plan, execute and expand this strategy in the territory, the Animal Vaccination Institute (1873) and the General Vaccine Center (1883) to produce it. In the twentieth century, it became mandatory by law and together with strict isolation measures taken on cases and spot checks, led to the elimination of the disease in 1923.

KEY WORDS: Smallpox; health; vaccination; history of vaccination; Tomas Romay; Cuba; XIX-XX Century.

Copyright: ( 2020 CSIC. Este es un artículo de acceso abierto distribuido bajo los términos de la licencia de uso y distribución Creative Commons Reconocimiento 4.0 Internacional (CC BY 4.0). 


\section{INTRODUCCIÓN}

La viruela, fue una enfermedad que estuvo presente desde los primeros años de la colonización de Cuba, pues se ha documentado su presencia, en fecha tan temprana como 1520, con un brote epidémico confirmado un año después (Martínez Fortun, 1952) y, como luego comentaremos en detalle, la presencia de la enfermedad en el siglo XIX y los inicios del XX, continuó siendo un problema que la sociedad cubana, tuvo que afrontar.

En el marco de los estudios históricos sobre vacunación antivariólica en Latinoamérica, ocupan un lugar destacado los realizados en torno a la figura del médico cubano Tomas Romay y Chacón (1764-1849). De él se ha subrayado (López Sánchez, 2004), con todo merecimiento, no solo su papel destacado en relación con la difusión de la citada vacuna en su país, sino también por ser uno de los pioneros e impulsores del proceso de modernización social y sanitaria cubanos de su tiempo, como importante miembro de la Real Sociedad Económica de Amigos del País (RSEAP) ${ }^{1}$, como uno de los redactores del Papel Periódico de La Havana así como su vinculación a la universidad llegando a ser decano de la Facultad de Medicina.

Romay, junto con otros científicos, formaría parte de lo que López Sánchez denominó "Año de la eclosión científica" (1797) (López Sánchez, 2016) integrado por quienes publicaron por primera vez y al unísono un grupo de trabajos que abrieron el camino de la literatura científica en el país. Como parte de ese grupo, del que fue uno de los fundadores, publicó una Disertación sobre la fiebre maligna llamada vulgarmente vómito negro, enfermedad epidémica de las Indias Occidentales (Romay, 1797, ed 1965, T 1, p. $65-84)$, donde hizo un estudio sobre la fiebre amarilla, que era una de las causas fundamentales de la mortalidad en la época. Y, finalmente, su compromiso político y social fue innegable, formado parte de la RSEAP (Beldarrain, 2010).

Pero Romay es sobre todo conocido por ser el principal artífice de la introducción en el país de la vacuna antivariólica, iniciada por él, antes de la llegada a las costas cubanas de la Real Expedición Filantrópica de la Vacuna (1803-1806), comandada por Francisco Xavier Balmis, para propagar el preservativo en los dominios españoles. La producción científica sobre Balmis y la Expedición es muy abundante y la monografía de Susana M. Ramírez Martín (Ramírez, 2002a), reuniendo trabajos previos y otras aportaciones posteriores en colaboración con otros autores, ha supuesto un hito fundamental en el conocimiento histórico de la Expedición por su rigor y su impecable trabajo en fuentes originales. Dentro del itinerario de la Expedición conocemos que el 27 de marzo de 1804 arribó a La Habana, aquí estuvo hasta el 18 de junio del mismo año, que se dirigió a Yucatán. La propia autora subraya la influencia de Romay en España. Al médico cubano, desde la Inclusa madrileña se le solicita, en 1813, información sobre su procedimiento de manejo del fluido vacunal. La respuesta de Romay y la documentación de archivo generada, fue reproducida por Ramírez en su trabajo publicado en Asclepio (Ramírez, 2002b), El recurrir a Romay se debió, tal y como subraya Ramírez, a un doble motivo: por su trayectoria como vacunador $y$, en segundo lugar, por su pertenencia a la Junta de la Real Casa de la Beneficencia de extramuros de La Habana.

Contó, para estas actividades científicas, con el apoyo del Obispo de La Habana, monseñor Don Juan José Díaz de Espada y Fernández de Landa y de la ya mencionada RSEAP de La Habana.

Como analizaremos más adelante, la vacunación, que se extendió durante todo el siglo XIX, promovió el surgimiento de instituciones, como la Junta Central de la Vacuna (1804), encargada de todo lo relativo a su propagación y de otras para la producción de la misma, como fueron el Instituto de Vacunación Animal (1873) y el Centro General de la Vacuna (1883). Mediante una legislación, en los primeros años del siglo XX, la vacunación se hizo obligatoria.

En el periodo que se desarrolla el artículo, Cuba fue una colonia de España durante todo el siglo XIX, en sus inicios, la actividad económica fundamental era la producción de azúcar, para la exportación hacia Europa y los Estados Unidos de América (EUA), la base fundamental del desarrollo de esta industria fue la esclavitud, que se incrementó desde mediados del siglo XVIII. Desde 1789 hasta principios del siglo XIX, se importaron 30475 esclavos (Ely, 2001, p. 49 - 50). Por ejemplo, en 1822, Cuba le vendió a los EUA 41 361000 lb de azúcar prieta y 10602000 lb de azúcar blanca, valuadas en conjunto por la aduana norteamericana en 3000000 de dólares, y 6191000 galones de mieles en 1100000 dólares. Para ese año Cuba era el principal productor del dulce en el mundo (Ely, 2001, p.76; Moreno Fraginals, 1986).

A partir de 1868 , se inició un período convulso, de guerras por la independencia nacional, hasta 1898, se sucedieron tres: la Guerra de los Díez Años (1868 - 
1878), la Guerra Chiquita (1871) y la Guerra de Independencia (1895 - 1898), etapa que se deterioraron mucho las condiciones sanitarias de la isla, así como su actividad económica. En enero de 1999 y hasta 1902, ocurrió la Primera Intervención Militar Norteamericana, que trató de mejorar la situación higiénica y controlar algunas enfermedades epidémicas, creando nuevas instituciones. El período final del artículo, coincide con los primeros años de la República, iniciada el 2 de mayo de 1902, donde la economía paso a depender muy estrechamente de los vecinos del norte y el azúcar continuó como su principal producción.

El objetivo del presente artículo es analizar los resultados de la estrategia de vacunación en la eliminación de la viruela en Cuba en el periodo objeto de estudio. El inicio, en 1804, se justifica por tratarse de la fecha de introducción de la vacuna jenneriana en Cuba. La finalización del trabajo en 1923, viene dada por ser el año siguiente al que se produjo el último caso de viruela en la isla. Un segundo objetivo general es el análisis de cómo se transformaron las instituciones en relación a los avances y producción de la vacuna en los diferentes contextos en los que se llevó a cabo, coincidentes en gran parte, con acontecimientos políticos importantes que marcaron el tránsito de colonia a estado nacional en Cuba.

\section{METODOLOGÍA}

Para lograr estos resultados se utilizó el método histórico lógico, apoyados en la técnica de la revisión documental. Se revisaron las estadísticas de salud sobre viruela, disponibles en la Dirección Nacional de Estadísticas y Registros Médicos, del Ministerio de Salud Pública, documentos existentes en el Archivo Nacional y en la Oficina del Historiador de la Salud Pública, relacionados con las instituciones encargadas de propagar y producir la vacuna, así como, los informes elaborados por estas instituciones y artículos científicos publicados, relacionados con el tema, en la prensa médica nacional.

\section{LA DIMENSIÓN EPIDEMIOLÓGICA DE LA VIRUELA EN CUBA}

En Cuba, existieron epidemias documentadas desde etapas tempranas del encuentro de los dos mundos. Los primeros grandes brotes de enfermedades infecciosas que se conocen, datan de la etapa inicial del proceso de conquista - colonización, cuando la población aborigen de su territorio, se puso en contacto con la europea, con lo que se introdujeron algunas enfermedades hasta entonces desconocidas como viruela, gripe y sarampión, entre las primeras, con gran virulencia y una letalidad elevada (Beldarraín, 2010). La relación entre colonialismo y presencia de brotes epidémicos desconocidos con anterioridad, así como su influencia en el desarrollo de políticas de salud pública, ha sido un tema especialmente relevante desde el punto de vista historiográfico en los últimos años. Para el conjunto de Latinoamérica, el trabajo conjunto de Cueto y Palmer es de gran utilidad (Cueto y Palmer, 2014).

La presencia de brotes epidémicos fue una constante desde el siglo XVI a los inicios del XX en Cuba. La enfermedad continuó, causando enfermedad y muerte en la Isla, por cuatrocientos años, hasta que se eliminó, en 1923 (cuadro No. 1).

Cuadro No. 1. Años en que se desarrollaron las principales epidemias de viruela registradas en Cuba. Siglos XVI -XX

\begin{tabular}{|c|c|c|c|c|}
\hline \multicolumn{5}{|c|}{ Epidemias de Viruela } \\
\hline Siglo XVI & $\begin{array}{l}\text { Siglo } \\
\text { XVII }\end{array}$ & $\begin{array}{l}\text { Siglo } \\
\text { XVIII }\end{array}$ & Siglo XIX & Siglo XX \\
\hline $\begin{array}{l}1521 \\
1530 \\
1570\end{array}$ & 1637 & $\begin{array}{l}1709 \\
1770\end{array}$ & $\begin{array}{c}1804 \\
1807 \\
1816 \\
1817 \\
1819 \\
1821 \\
1829 \\
1830 \\
1833 \\
1840 \\
1844 \\
1834 \\
1852 \\
1860 \\
1862-1863 \\
1866-1867 \\
1870-1873 \\
1877-1879 \\
1881 \\
1887-1888 \\
1896\end{array}$ & 1921-1922 \\
\hline
\end{tabular}

Fuente: Datos compilados por el autor de diversas fuentes para el presente trabajo (Martínez - Fortún, 1952; López Sánchez, 1997 y 2004; Le Roy Cassá, 1922 y Delgado García,1987 y 1991). 
La primera epidemia de viruela de que se tienen noticias, data de 1521 . Se sabe de la existencia de casos de la enfermedad desde el año anterior (Martínez - Fortún, 1952, p. 28). Según los datos del historiador Jacobo de la Pezuela, fue una enfermedad muy severa, la que dejaba una gran cantidad de bajas en los indios (Pezuela, 1868, T 1, p. 112). El testimonio del padre Bartolomé de Las Casas, sitúa el inició del brote en 1518 o 1519, en la isla de La Española después atacó a Puerto Rico, en enero de 1519, y llegó a Cuba, en 1520 (López Sánchez, 1997, p. 24).

El demógrafo e historiador Juan Pérez de la Riva, estimó la población indígena cubana en unos 112 000 habitantes, con un elevado índice de reducción, que, en 10 años, alcanzó un 80\%, estas cifras estiman que cuando ocurrió la severa epidemia de viruela, quedaron unos 18700 indocubanos, para el año 1521, por lo que fue la causa, según este autor, de la mortalidad del $33 \%$ de la población, que ya tres años antes (1518) había disminuido a unos 60 000 habitantes, o sea la mitad (Pérez de la Riva, 1972). Otros criterios argumentan que por muy severa y explosiva que haya sido esta epidemia, estos cálculos son exagerados, más con las características habitacionales que tenía la población aborigen, la cual vivía muy dispersa con una densidad relativa baja (López Sánchez, 1997, p. 41 - 42).

Durante este siglo XVI existieron epidemias variolosas en 1530 y 1570 (Martínez- Fortún, 1952, p. 30). En el siglo XVII, en 1637, se presentó la viruela, en La Habana, siguieron brotes de diferente intensidad en todo el siglo y a partir de 1649 , estos se alternaron con las epidemias de fiebre amarilla, durante los dos siglos posteriores. (López Sánchez, 1970, p. 97).

En el siglo XVIII, hay evidencias de coexistir un brote de fiebre amarilla y otro de viruela en 1709. Una epidemia variolosa ocurrió en 1770, que duró mucho tiempo en la capital, referidas en las actas capitulares. (Martínez-Fortún, 1952, p. 30).

Iniciando el siglo XIX, en 1804, estuvo presente la enfermedad con focos en numerosas villas y poblados. A pesar de la introducción de la vacuna en esas fechas, el mal se presentó los años siguientes en diversos lugares del territorio. En 1816, fue importante una epidemia de viruela, coexistiendo con una de fiebre amarilla y otra de anginas graves (tos ferina). En 1817, se agravó junto a la fiebre amarilla en La Habana y, en 1819, ambas enfermedades continuaron azotando a la población cubana (Martínez-Fortún, 1952, p. 30).
Todo este siglo, se presentaron brotes de viruela, informándose en 1821 una epidemia grave de ella en Santiago de Cuba. En 1829, todo el territorio insular se vio afectado por una presencia severa de esta enfermedad, de la que Romay dijo ser grave, y continuó su difusión en el año siguiente. Se corroboró un brote, en la villa de Remedios en 1840 (Martínez-Fortún, 1952, p. 31).

Santiago de Cuba se vio afectada nuevamente por una epidemia variólica en el verano de 1844 y en 1852, en La Habana (Martínez-Fortún, 1952, p. 3132). Entre 1860 y 1863, se informó la existencia de este mal en diversas poblaciones de la isla, produciendo elevada mortalidad. La de 1860, ocasionó 355 muertes en la capital, en 1861, fallecieron por esta causa, 367 personas y la epidemia en Remedios, causó 871 víctimas. En 1862, llegó este virus a Santa Clara, y en 1863 de nuevo en Remedios (Le Roy, 1913).

A pesar de la vacunación contra la viruela, iniciada por Tomás Romay en 1804 y mantenida sistemáticamente como medida, sus epidemias se hicieron presentes en 1871, 1878, 1887, y 1896 (cuadro No 1). La más grave fue la de 1887-88, que provocó, 2204 muertes en estos dos años, que coincidieron con la guerra de los Diez Años (cuadro No. 2). El mayor número de fallecidos, se registró en el año 1878, al finalizar la Guerra de los Diez Años (Sesión pública del 23 de octubre de 1881. Anales Acad Med Fis Nat Hab. 1882; 18: 277-79).

Cuadro No. 2. Defunciones por viruela durante la guerra de los 10 años

\begin{tabular}{|c|c|}
\hline Año & Defunciones \\
\hline 1871 & 186 \\
\hline 1872 & 174 \\
\hline 1873 & 47 \\
\hline 1874 & 772 \\
\hline 1875 & 711 \\
\hline 1876 & 160 \\
\hline 1877 & 99 \\
\hline 1878 & 1225 \\
\hline
\end{tabular}

Fuente: Estadísticas de González del Valle.

En 1887, la viruela, ocasionó sólo en la capital, 1 654 defunciones. Se recogió presencia de brotes en Batabanó, Mariel, y Cienfuegos, además de los de Remedios, Matanzas, Regla y La Habana. Desde 1899, 
no se presentó una epidemia importante variolosa en ese siglo en Cuba (Le Roy, 1922).

En el siglo XX, no se encontraron datos de incidencia de esta enfermedad en los años correspondientes a 1905 - 1909. No hubo defunciones por la misma entre los años 1910 y 1913, ni desde el 1916 al 1918. Se reportó una epidemia, que causó la mayoría de los fallecidos, se reportaron 316 muertes en 1921, que elevó la tasa de mortalidad a $10.43 \times 10^{5}$ habitantes, el año siguiente, se contabilizaron 158 exitus letales, que representaron una tasa de mortalidad de $5.08 \times 10^{5}$ habitantes (figura No. 1). En estos dos años, se notificaron 493 fallecidos. La viruela fue erradicada de Cuba desde 1923 (Martínez-Fortún, 1952, p. 37 - 51).

Figura No. 1. Mortalidad anual de viruela en Cuba. Años 1904-1922.

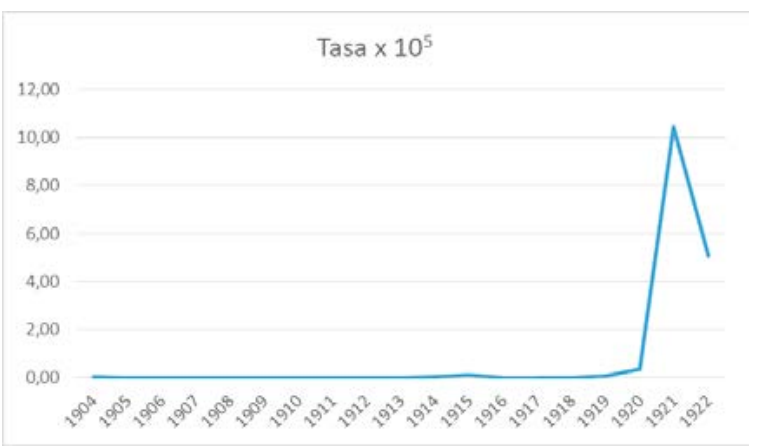

Fuente: Departamento de Estadística. MINSAP.

\section{INTRODUCCIÓN, PROPAGACIÓN Y CONSERVACIÓN DE LA VACUNA ANTIVARIÓLICA}

\section{TOMAS ROMAY Y LOS INICIOS DE LA VACUNACIÓN EN LA PRIMERA MITAD DEL SIGLO XIX}

Los esfuerzos de Tomás Romay por lograr disponer de una vacuna fueron titánicos, pues comprendió que era el único medio disponible para enfrentar la enfermedad y no paró hasta tenerla en sus manos. La comunidad facultativa habanera supo de este proceder en 1802 , hasta ese momento se utilizaba la variolización, que no era más que la inoculación con el virus varioloso, que lo practicó el propio Romay, desde tiempo atrás² (López Sánchez, 2004, p. 81).

La RSEAP, en sesión del 4 de febrero de 1802, el Censor, Don Andrés de Jaúregui, comunicó, que había recibido una memoria impresa en Madrid, sobre el uso y propagación de la vacuna, para que se estudiara y dictaminara sobre la oportunidad de su uso. De hecho, el método de vacunación jenneriana fue conocido en Cuba a través de la difusión de la obra de Pedro Hernández (Hernández, 1802), que se editó en Madrid y más tarde en La Habana y México (Ramírez, 2002b, p. 113). La Junta de Gobierno decidió que Romay, la estudiara e informara si era ventajoso que se imprimiera y se diera a conocer a los médicos para que se familiarizaran con estas ideas nuevas (López Sánchez, 2004, p. 81; Libro de Acuerdos de la Sociedad Económica, Libro II, folio 458, p. 55). Éste, estudió el complejo problema de la vacunación en toda su extensión y vislumbró lo ventajoso de su utilización. Desde ese momento fue su defensor e inició un trabajo en la dirección de introducir, sostener y expandir esta técnica en toda la isla. También estas nuevas ideas le proporcionaron distanciarse de los inoculadores y le ofrecieron respaldo para iniciar una batalla en su contra, que fue una manifestación de un debate ideológico y epistemológico, que tenía su origen en conflictos metodológicos y de conocimiento científico, pero era en realidad un problema profesional, un elemento de protección gremial, y prescindir de la rivalidad que representaban los inoculadores.

La vacunación, le permitió a los galenos y a las autoridades que la respaldaron luchar contra la enfermedad, en el campo profesional, sentó las bases de la prevención de las enfermedades, y fue un elemento importante que podría contribuir a erradicar un problema social acuciante, representado por la morbilidad y mortalidad que la viruela ocasionaba en la población. Fue también el primer proyecto social de la medicina cubana

La vacuna fue distribuida gratis y fue la primera vez en la Isla, que se proponía desde las instituciones, desde el poder, una medida de protección a cualquier miembro de la sociedad, sin costo alguno y sin que fuera una fuente de ingresos para ninguno de los involucrados, ya fueran los profesionales o las instituciones. Se puede decir que, fue la primera manifestación de medicina social en Cuba (Beldarraín, 2010).

El Real Tribunal del Protomedicato se pronunció a favor de la vacunación. Romay, recomendó que se publicara el opúsculo sobre la vacunación y dijo que lo más importante era buscar el pus infeccioso en vacas afectadas, para poder iniciar la vacunación entre la población. La RSEAP, solicitó al Real Consulado, que se encargara de imprimir el folleto sobre la vacunación, lo que se hizo efectivo, el 25 febrero 1802 (López Sánchez, 2004, p. 84; Libro de Acuerdos de la 
Sociedad Económica, Libro II, folio 458, p. 55). La RSEAP puso en manos de Romay todo lo relacionado con el inicio de la práctica de la vacunación, para ello tuvo entre las tareas más difíciles, la de disponer del virus vaccinoso, fue en un momento en que una gran epidemia de la enfermedad se expandía por la Isla y era su deseo empelar esta nueva estrategia de combate. Recorrió gran parte del territorio, buscando lesiones en las vacas. No encontró la vaccina, pero no desistió de su búsqueda (Beldarraín, 2010).

El Real Consulado, encargó, por todo el continente americano el pus vaccionoso y hasta al Comando de Cádiz. El Capitán General, Salvador Muro Salazar, Marqués de Someruelos, puso en manos de Romay, los más amplios recursos económicos para obtener la vacuna, hecho sin precedentes en relación con un evento de salud (Beldarraín, 2010).

En el Papel Periódico de la Havana, en la edición del 3 de febrero de 1803, se publicó la noticia de que se habían creado dos premios: uno de 400 pesos para quien descubriera y manifestara el fluido vaccino tomado de las vacas de esta isla, y otro premio de 200 pesos, para quien la trajera del extranjero (López Sánchez, 2004, p. 85). En ambos casos, Romay, tenía que certificar la veracidad y utilidad del fluido. El premio fue concebido por el Real Consulado.

Don Felipe Facio, transportó desde Filadelfia, tres cristales que contenían el pus vaccionoso, colectado en Filadelfia el 22 de enero y el 7 de febrero, los que entregó al capitán general marqués de Someruelos, el 22 de marzo, quién a su vez se los entregó a Romay. Este preparó rápidamente la primera aplicación del proceder y fueron sus propios hijos los escogidos. El resultado fue negativo, pues la vacuna no prendió. Sin embargo, los doctores Bernardo Cozar y Francisco Martínez, utilizaron el mismo pus vaccionso con éxito en un niño habanero (López Sánchez, 2004, p. 86).

En la primera quincena de febrero de 1804, Romay inició la vacunación en Cuba, pues el día 10, llegó a la capital, la señora María Luisa Bustamante, procedente de Aguadillas, Puerto Rico, de donde salió unos días antes y vacunó la víspera del viaje, a su hijo de 10 años y a dos sirvientas de 6 y 8 años, respectivamente. De ella obtuvo la ayuda necesaria y el preciado fluido, pues permitió que Romay lo tomara de las lesiones de sus acompañantes, así vacunó a su propia familia. La misma noche a sus dos hijos pequeños y, a la mañana siguiente, a los tres mayores, también a varios niños y criados, lo que le permitió vacunar después a 200 personas. Así cuando la expedición de Balmis arribó a la Isla, ya había iniciado la propagación de la vacuna (Beldarraín, 2010).

Para evidenciar el trabajo, fueron evaluadas, por los doctores Bernardo Cozar, ayudante del director de cirugía y medicina de la escuadra y hospitales de la marina de este puerto, Juan Pérez Carillo y Francisco Gutiérrez, segundos profesores médicos cirujanos de la Armada, los cuales habían visto la vacuna en España y Puerto Rico, los que ratificaron el éxito de la vacunación realizada (López Sánchez, 2004, p. 89). Un grupo numeroso y distinguido de facultativos, se dedicó desde entonces, a difundir la vacuna junto a Romay, entre ellos los doctores Bernardo Cozar, Juan Pérez Delgado, José Pérez Bohorques, Andrés Terriles, Francisco Martínez y los licenciados Marcos Sánchez Rubio y Manuel Hernández (Beldarraín, 2010).

En la ciudad de Santiago de Cuba, se introdujo la vacuna un mes antes que, en la capital, por el cirujano francés M. Vignard, procedente de Saint Thomas, quién vacunó a una niña con el virus que trajo entre cristales; logró la erupción de unos granos verdaderos y encargó de su propagación al doctor Miguel Rolland, quien realizó estas operaciones en la ciudad. Romay, fue el primero y el único que se trazó y llevó a cabo un plan de esa naturaleza y envergadura. En la vacuna, no se puede hablar de modo aislado de introducción, porque no tiene un sentido social si no va aparejado con su conservación y propagación. Esta estrategia se debió sin dudas a Romay, con el apoyo oficial (López Sánchez, 2004, p. 92; Beldarraín, 2010).

Romay, le explicó al Capitán General, la necesidad y urgencia de tomar medidas para conservar la vacuna, pues se corría el riesgo de su pérdida, en una carta la propuso un plan de diez aspectos a desarrollar para lograrlo. Fue una anticipación del proyecto propuesto posteriormente por Blamis de la creación de la Junta Central de la Vacuna (Beldarraín, 2010).

La Real Expedición de la Vacuna, dirigida por el doctor Francisco Xavier de Balmis, llegó a Cuba el 26 de mayo de 1804. Y encontró que desde febrero se propagaba la vacuna por la Isla, estuvo en La Habana 20 días y residió en la calle Obrapía No. 162, donde realizó cientos de inoculaciones en este poco tiempo. Es preciso destacar el ambiente favorable que ya existía en la ciudad en relación con la prevención de la viruela por esta técnica. Para perpetuar la vacuna, 
Balmis determinó inocular algunas vacas con el virus, porque presumía que al comunicársela a estos animales se haría la enfermedad epidémica entre ellos. Para esta tarea, solicitó la ayuda de Romay (Beldarraín, 2010).

Antes de su marcha, Balmis, presentó un plan científico y económico, para establecer una Junta que conservase inalterable el fluido vacuno. Asimismo, recomendó al gobierno, que hasta se resolviese sobre ello, era Romay, el más indicado para que se le confiara "como un depósito, el más precioso e importante: la conservación del virus vacuno en esta ciudad" (López Sánchez, 2004, p. 93; Beldarraín, 2010).

\section{La Junta Central de la Vacuna (1804 - 1849)}

La RSEAP acogió con beneplácito las propuestas del doctor Balmis para establecer una difusión adecuada de la vacuna y en la sesión del 8 de junio de 1804 , se leyó una carta enviada por este galeno, donde expresaba su placer de que antes de su llegada ya Romay practicara la vacunación, también envió un reglamento para conservar el fluido vacunal y propuso se creara una institución para ello: la Junta Central de la Vacuna (Libro de Acuerdos Sociedad Económica, Libro 3, folios 133 y 136, p. 60). Unos días después, el 13 de junio, Romay recibió toda la documentación pertinente, donde quedaba constituida la institución y él mismo fue nombrado Secretario Facultativo, cargo que ejerció hasta su muerte con un rigor y cientificidad admirables.

Esta Junta inició las acciones de higiene pública y la primera medida general de carácter sanitario en la Isla, fue la vacunación.

Se constituyeron Juntas Subalternas en las diferentes ciudades y villas de la isla, en las cuales trabajaban vacunadores perfectamente entrenados, que llevaron adelante el trabajo de propagar la vacuna en los diferentes términos municipales. Estas juntas tuvieron una relación estrecha con la junta capitalina, enviaban informes periódicos del trabajo realizado, que fueron integrados en la estadística que elaboró la institución central.

Los Ayuntamientos de las diferentes villas de la Isla, asumieron los gastos que acarrearon los trabajos de vacunación en su jurisdicción. En algunas oportunidades, el Ayuntamiento habanero fue moroso con el pago de los adeudos, su Secretario Facultativo, envió una misiva a la presidencia de la RSEAP, donde recordó los acuerdos existentes y los compromisos contraídos por los ayuntamientos, de manera espontánea, para mantener el trabajo de conservación y propagación de la vacuna (Archivo de la Sociedad Económica, Legajo No. 5, Apéndice E).

La Junta Central de la Vacuna funcionó hasta 1849, cuando falleció Romay, entonces sus funciones pasaron a las Juntas Superior, Provinciales y Municipales de Sanidad, que desde entonces designaron y supervisaron a los vacunadores hasta el final de la dominación española (Delgado, 1987; Beldarraín, 2010).

Fue destacada la actuación del vacunador licenciado Joaquín José Navarro, quien trabajó en Santiago de Cuba. Sostuvo que era imprescindible inocular las vacas, a partir del pus de los granos vacunos del hombre, para conservar inalterable el virus (López Sánchez, 2004, p. 99).

Gran importancia tuvo la decisión de la Junta Central de la Vacuna, de establecer la obligatoriedad de la vacunación. Romay, propuso además que no se admitiera en ningún colegio a un alumno si no se acompañaba de un certificado de vacunación antivariolosa. Una de sus medidas más importante, fue la vacunación obligatoria a todos los esclavos que llegaban al puerto de la ciudad, antes de permitirse su venta, y si alguno había padecido la viruela durante el viaje, se hacía observar a todos los tripulantes y esclavos la más rígida cuarentena (Delgado, 1996, p. 32; Beldarraín, 2010).

Durante el siglo XIX, la única medida de lucha posible contra la enfermedad era la vacunación, se había creado una institución capaz de propagarla y establecer una estrategia para su control: la Junta Central de la Vacuna, a pesar de sus esfuerzos, los resultados de la vacunación fueron bastante pobres, al igual que la cobertura de población vacunada.

\section{LA VACUNACIÓN DESPUÉS DEL CIERRE DE LA JUNTA CENTRAL DE LA VACUNA}

\section{La Junta Superior Provinciales y Municipales de SANIDAD}

La vacunación antivariolosa, a partir de 1849 , se integró en la estructura institucional sanitaria de la colonia. Esta organización sanitaria estaba integrada por la Junta Superior de Sanidad, que se estableció 
en 1807, pero la misma tuvo una acción muy limitada, ya que no se destacó por establecer un control de las enfermedades infectocontagiosas existentes, ni tan siquiera por elaborar planes o establecer medidas para intentar su control, hasta 1825 , en que se documentó una epidemia de dengue y entonces, dicha Junta si tuvo por vez primera una gestión apropiada y pocos años después, en 1832, cuando el fantasma del cólera amenazaba con atacar a la isla, se creció y fue verdaderamente una institución operativa. Pero la epidemia de cólera, que finalmente alcanzó al territorio en 1833, fue tan brutal, que desbordó a todo el marco institucional colonial, incluida la misma Junta, la cual fue disuelta en enero de 1834 , así como el Real Tribunal del Protomedicato, que existía desde 1711 (Delgado, 1996, 35 - 43).

En esta primera etapa del siglo XIX, contrastó, con estas instituciones, el servicio de la Junta Central de la Vacuna, que tuvo un trabajo sistemático y con resultados tangibles.

En enero de 1834, inició su labor la Junta Superior Gubernativa de Medicina y Cirugía y la de Farmacia, la primera asumió todas las tareas que tenía la antigua junta sanitaria y las del Protomedicato. Posteriormente, estas instituciones se reformaron en parte y se les llamó Juntas Superior de Sanidad, la cual tuvo instancias locales: Juntas Provinciales y Juntas Municipales de Sanidad, desde 1842.

A partir de este año, las actividades de vacunación fueron de la jurisdicción de esta junta, la cual continuó este trabajo, pero con menor fuerza que cuando era dirigida por Romay, se mantuvieron las acciones y el entrenamiento sucesivo de los vacunadores, en las diferentes localidades del país.

\section{La Real ACademia de Ciencias Médicas, Físicas Y Naturales de LA Habana}

La Real Academia de Ciencias Médicas, Físicas y Naturales de La Habana (RACMFNH) fue la institución científica más relevante de la isla de Cuba en toda su etapa colonial, se inauguró en 1861 , se destacó principalmente como una tribuna de discusión y un motor propulsor del desarrollo y difusión de las ideas científicas nuevas, además de organismo asesor del Gobierno colonial en materia de medicina y de las restantes ciencias. Estuvo involucrada también en el control de la viruela a través de la vacunación.
La RACMFNH, fue también un centro asistencial de vacunación. El 12 de septiembre de 1869, se informó, que el director de vacunación en La Habana, doctor Vicente Hernández, había solicitado a la institución que un día a la semana se administrara en su salón de sesiones el preservativo de la viruela (Anales, 7: 171, 1869).

El cuerpo de vacunadores de la Academia, que formaba la llamada Sub Comisión de la Vacuna, adscrita a la Comisión de Higiene Pública, Medicina Legal y Policía, estuvo encabezada por el doctor Rafael Hondares, eficazmente auxiliado desde 1869, por Tomás Mateo Govantes, quien sustituyó a Hondares, a su fallecimiento en 1877 (Anales, 13: 594, 1877), mantuvo informada a la Academia de la labor de la subcomisión, la cual practicó en 1876, 551 vacunaciones y repartió 305 tubos (capilares) con la linfa vacunal.

La corporación, era también un centro de distribución de la vacuna, que le era solicitada desde lugares muy lejanos. Por ejemplo, en 1877, se enviaron seis tubos a Bayamo, al año siguiente, varios a Santi Spíritus, en 1879, a Cabañas y Quivicán, en 1880, a Los Palacios y Cabañas, en 1881, a Madrugas y Puerto Príncipe, etc. (Pruna, 2002, p. 348).

En 1880, la subcomisión de la vacuna se trasladó a Santiago de las Vegas, para auxiliar a los colegas del lugar, pues el inóculo no prendía. Ese año formaron parte de la subcomisión, además de Govantes, José Pantaleón Machado, Vicente Benito Valdés, Miguel Riva, José Beato, Rafael A. Cowley y Gabriel Ma. García (Anales, 17: 23, 1880).

La RACMFNH, siempre prefirió la propagación de brazo a brazo, procedimiento que se practicaba desde 1804 y se utilizó al principio de las casas de socorro en 1871 (Le Roy, 1922, p. 11). La vacunación brazo a brazo, en lugar del uso directo de la linfa u otros componentes del cow - pox inducido en terneros, tenía el inconveniente, además del riesgo de propagar algunas enfermedades, de que a menudo se agotaba el suministro de la vacuna (la pústula del brazo del inoculado) y era necesario acudir a la importación de la linfa del extranjero, para reiniciar la cadena de inoculaciones de persona a persona. La primera remesa de linfa vacunal, adquirida por la Academia en el extranjero, consistió en seis tubos, remitidos por el Establecimiento Nacional de la Vacuna de Londres, del recibo se informó en sesión pública, el 12 octubre 1873. Posteriormente se compraron en varias oportunidades en 
el mismo establecimiento, sufragadas por el presidente Nicolás J. Gutiérrez (Pruna, 2002, p. 349).

\section{LAS CASAS DE SOCORRO}

En 1871, se inauguraron las Casas de Socorro, instituciones de atención primaria de salud, que atendían a la población de los barrios donde estaban ubicadas, brindando atención médica de diverso tipo, tenían consultas, cuerpos de guardia, para la atención de urgencias. Entre sus servicios estuvo el departamento de vacunación, donde realizaban vacunaciones y revacunaciones a las personas que acudían a ello. Esta vacunación era gratuita y por iniciativa del director de vacunación y concejal doctor Vicente Hernández, se realizaban brazo a brazo. Estas instituciones llegaron a ser siete en la capital y estuvieron funcionando hasta la primera mitad del siglo XX (Le Roy, 1922, p. 11).

\section{EL INSTITUTO de Vacunación ANimal}

Las autoridades sanitarias de la Isla, tratando de resolver el problema de la inestabilidad existente con el suministro de vacuna, comisionaron al doctor Vicente Luis Ferrer, para que, por sus propios medios, viajara a Europa, donde visitó varios países que habían sustituido la vacunación brazo a brazo, por el uso directo del suero vaccinal de terneros y examinara la conveniencia, de implantar en Cuba la vacunación animal. Regresó en 1868, con dos terneros que padecían viruela vacuna (Le Roy, 1922). En el propio año, comenzó a practicar la vacunación animal en las ciudades de Matanzas, Colón y Guanajay, y ya el 27 de agosto, una Real Orden, lo autorizó a establecer un Instituto de Vacunación Animal de las Islas de Cuba y Puerto Rico. El reglamento de esta entidad privada se discutió en la Academia, en sesión pública del 10 de septiembre de 1869 (Anales, 14: $533,1878)$.

La discusión, si la vacunación debía propagarse de persona a persona o de terneras que la padecían a personas, se prolongó, desde 1869 hasta 1898. Influía mucho, la situación que los médicos se habían acostumbrado a la vacunación brazo a brazo, aunque ya en 1878 , las casas de socorro utilizaban solo la vacuna animal. Había dudas también, sobre la efectividad de esta vacuna. En 1879, se realizó una prueba experi- mental en la Academia, que no arrojó diferencias entre la vacuna de brazo y la animal, la corporación siguió prefiriendo la forma tradicional (Pruna: 350).

El Instituto de Vacunación Animal comenzó a producir vacunas, y a aplicarla a la población que allí acudía, fue una institución privada, creada y dirigida por el doctor Vicente Luis Ferrer, su vacuna debía ser comprada, por lo que no era accesible a los estratos inferiores de la población colonial. La que continuaba proporcionando la RACMFNH era gratuita.

No resultaba concebible, para los doctores Gutiérrez, Mestre, Govantes y muchos otros académicos, que la campaña de vacunación iniciada por Romay, a principios del siglo, que uno de sus pilares era su carácter gratuito, y fue de los factores que le permitió prevalecer sobre la variolización, que se practicaba hasta entonces en Cuba, se convirtiera en un elemento de lucro. De ahí que la vacunación animal, nunca fuera bien vista en la Academia.

Según Le Roy, el Instituto de Vacunación Animal: “... fue el primer establecimiento de su índole creado en las Américas, y surtió a otros varios de la Isla y del extranjero. Los distintos preparados que usaba ese centro, eran pústulas frescas, cultivadas de ternera a ternera, cortados en los días 50 y 60 de su evolución y conservados en papel de plomo o en yeso, y la linfa extraída de las mismas conservada en tubos capilares, entre cristales, en puntas de marfil o en plumas de aves, y pústulas en glicerina. Más tarde, usó además del glicerinado de vacuna, un preparado con glicerinado de almidón y la parte pulposa de las pústulas" (Le Roy, 1922, p. 12).

En 1871 apareció la revista El propagador de la vacuna, editad y dirigida por el doctor Vicente Luis Ferrer, estaba concebida para publicar noticias y artículos que reflejaran la realidad sobre la vacunación antivariólica y dotara a los estudiantes de medicina, a los galenos y a la población en general con sólidos conocimientos sobre el tema. Incluiría información sobre la legislación existente alrededor de la vacuna, así como las noticias y adelantos del instituto que él dirigía. Se conoce un solo número, aunque en su editorial, el director anuncia un segundo número, dirigido a las madres, que al parecer nunca se publicó. Este primer número lo dirigió a los hacendados, e incluye un artículo sobre el estado de la vacunación en los campos cubanos, acompañado con tablas estadísticas, de la situación de las vacunaciones en di- 
versas fincas y los resultados alcanzados (López Espinosa, 2004).

El Instituto de Vacunación Animal, continuó después de la muerte de su fundador en 1883, tuvo como directores a los doctores Diego Tamayo (18831885), Antonio Díaz Albertini y Enrique Porto (1885 - 1892) y José Luis Ferrer (1892 en adelante), hijo de su fundador (Le Roy, 1922, p. 13). Al parecer, en 1886, se denominaba Instituto Práctico de Vacunación Animal. Bajo la dirección de Díaz Albertini y Porto, comenzó la producción de una pulpa vaccinal extraída de la ternera, según procedimiento del Instituto Vaccinifero de Bélgica, de ello se informó en la academia, en sesión pública del 11 de abril de 1886, pues habían enviado una muestra a la subcomisión de la vacuna (Pruna, 2002, p. 352).

\section{LA VACUNACIÓN EN LOS ÚlTIMOS AÑOS DEL SIGLO XIX}

Los años finales del siglo XIX, se caracterizaron epidemiológicamente por la presencia de varias enfermedades infectocontagiosas, entre las más importantes se documentaron la fiebre amarilla, el paludismo, la disentería, la tuberculosis y la viruela. Estas se incrementaron notablemente en la segunda mitad de década de 1890, cuando comenzó la Guerra de Independencia (1895). Las autoridades políticas y sanitarias coloniales, no mostraron mucho interés en la solución de estos problemas, estaban más preocupados por controlar la situación de inestabilidad política existente y la conclusión inminente de la pérdida de uno de los últimos territorios de imperio español (a esas alturas solo le quedaban Cuba, Puerto Rico y las Filipinas). No obstante, algo se hizo para tratar de continuar la lucha contra la viruela, única enfermedad de las presentes que tenía una medida específica para enfrentarla. Se vieron conminados a la acción, por la presión y el reclamo de los médicos cubanos, que eran bastante numerosos e influyentes en la sociedad de esos momentos y algunas instituciones demasiado poderosas en relación con la formación de opinión pública, como fueron la RACMFNH y la RSEAP (Martinez-Fortún, 1952; Beldarraín, 2014; Funes, 2005).

Esta situación, llevó a las autoridades a crear en 1890 , de un centro público para la producción y propagación de la vacuna, y más adelante de varias instituciones similares, de carácter privado, que expendían sus propias producciones, lo que ayudó a la difusión de la vacuna.
En los años previos, la RACMFNH, continuó la propagación brazo a brazo y en, 1880, extendió estos servicios a otro centro de vacunación, que con el nombre de "Tomás Romay" se inauguró en la RSEAP.

El doctor Govantes, informó que mientras más revacunaciones recibía un individuo, menos eran las posibilidades de que falleciera como consecuencia de la viruela, en la sesión pública del 27 de octubre de 1880. Joaquín de Zayas, comunicó su observación del efecto sedante y antipirético del ácido salicílico en un caso de viruela (Zayas, 1881, 418).

En 1881, la Academia recomendó al gobierno que la vacunación antivariólica se hiciera obligatoria (Anales, 17: 506 - 08, 1881). De acuerdo a la legislación vigente en España, en Cuba debía crearse un Centro General de la Vacuna, y el Gobierno de la isla indicó a la Academia, que elaborara un proyecto de reglamento para el mismo.

El 9 de octubre de 1887, Vicente de la Guardia, presentó un detallado informe sobre la epidemia de viruela desatada ese año (Anales, 24: 579, 1888).

La epidemia continuó en 1888, y el académico Miguel Franca Mazorra, propuso una serie de medidas prácticas a ser aplicada de inmediato, entre ellas la obligatoriedad de la vacuna y señalaba, que, el aislamiento de los enfermos era esencial, que se había comenzado a practicar sistemáticamente en los hospitales desde el brote epidémico de 1887 - 88, incluso se llegó a crear un hospital de variolosos, situado en el suburbio de La Miranda, que se clausuró al reducirse la incidencia de la enfermedad en 1888 (Anales, 25: 31, 33, 1888).

A finales del siglo, el 27de febrero de 1898 , se debatió en la Academia, un informe, de Juan Santos Fernández, sobre un trabajo del destacado galeno mejicano Eduardo Liceaga, donde se refería a los inconvenientes de la vacunación brazo a brazo, y se designó una comisión para que redactara una cartilla para la población sobre la vacunación antivariolosa.

A pesar de todos estos esfuerzos realizados, la vacunación no llegaba a toda la población, al menos de manera efectiva, con revacunaciones. 


\section{EL FIN DE LA ETAPA COLONIAL Y LA INTERVENCIÓN MILITAR NORTEAMERICANA (1899 - 1902)}

El siglo XX, en Cuba, se inició con la Primera Intervención Militar Norteamericana, que se caracterizó por un intenso trabajo sanitario, para tratar de solucionar la situación crítica presente en la Isla al final de la Guerra de Independencia, las villas fueron afectadas por el hambre y por un deficiente estado higiénico sanitario.

Los pobres vivían en desdichadas condiciones, entre miseria, hacinamiento, agravados por la falta de trabajo, que era muy elevada en las ciudades. Fue, una verdadera intervención sanitaria, tal vez lo único positivo de ese período, ya que no se pudo alcanzar, de momento, la libertad, por la que tantos cubanos habían luchado e incluso dado su vida.

\section{LA ORGANIZACIÓN SANITARIA EN EL PERIOdO DE LA PRIMERA INTERVENCIÓN NORTEAMERICANA}

En los primeros momentos de la administración norteamericana, se cancelaron las funciones de las Juntas de Sanidad en todos sus niveles; nacional, provinciales y locales, pues eran instituciones anticuadas que no podían dar una respuesta a los nuevos retos sanitarios a enfrentar. Los médicos militares norteamericanos organizaron bajo su mando, nuevos servicios sanitarios en casi todos los pueblos de la Isla. El Gobierno Militar, en enero de 1899, nombró un jefe de sanidad y abrieron los Departamentos de Sanidad de La Habana, Santiago de Cuba y las otras ciudades importantes. Estos nuevos centros tenían un Servicio de Inspección Sanitaria de Casas, el cual dividió a las poblaciones en distritos. La Habana quedó dividida en 100 distritos, y en cada uno se nombró a un médico inspector, escogido entre los médicos residentes en la ciudad. La fiebre amarilla y la tuberculosis, fueron enfermedades que recibieron una atención especial (Delgado, 1996; Beldarraín, 2014).

Fue nombrado Jefe de Sanidad, el mayor John Davies, quién solicitó a todos los galenos nacionales su ayuda para combatir el desastre sanitario del país. Así se organizó la Oficina Central de Sanidad que incluía cuatro Negociados: Órdenes, Estadísticas, Multas y Archivos. En abril de 1899, se fundaron los Servicios de Desinfección. Por una circular de la Secretaría de Guerra norteamericana del 17 de enero de 1889 se fundó el Servicio de Cuarentena (López Serrano, 1981; Beldarraín, 2014).

Estas instituciones sanitarias se encargaban de elaborar las estadísticas de natalidad, mortalidad, matrimonios, enfermedades y epidemias; eran responsables del control sanitario de los hospitales, asilos, hoteles, mataderos, escuelas, talleres, casas de vecindad, establos, cementerios y de todos los edificios públicos y cuarteles. Ejercían el control del agua y los servicios de alcantarillado, las basuras, el expendio de las bebidas, víveres y otros comestibles, para evitar su adulteración. Además, chequeaban el ganado de importación y la matanza en general, la declaración de enfermedades infectocontagiosas y el cumplimiento de las cuarentenas, el aislamiento y la desinfección de los atacados y de los lugares por estos contaminados. A ellos pertenecían también el servicio de vacuna y los servicios preventivos de carácter médico sanitario (Delgado, 1996; Beldarraín, 2014).

También surgieron los Servicios Sanitarios Municipales, que fueron dotados con un Reglamento General publicado en la Gaceta Oficial, el 3 de octubre de 1899. Estos servicios incluían las Casas de Socorro y la asistencia médica domiciliaria.

El mayor William Gorgas, fue nombrado Jefe de Sanidad en 1900, quién mandó a publicar por primera vez, oficialmente, las estadísticas sanitarias de La Habana y sus poblaciones limítrofes (López Serrano, 1981).

En esos años también se crearon las ramas de la Sanidad Marítima, el Departamento de Inmigración, el Servicio de Vacuna, el Servicio del Muermo y Tuberculosis en el Ganado y el de Higiene Especial. Cada una de estos servicios funcionaba de manera independiente. El 17 de mayo de 1902, por la Orden No. 159 , se creó la Junta Superior de Sanidad, la cual supervisaría los problemas e instituciones de salud pública y aplicaría las medidas sanitarias necesarias en el país. Esta Junta tenía potestad para hacer cumplir las leyes de carácter sanitario, con inclusión de las que regulaban el ejercicio de la medicina, la cirugía dental, las agencias funerarias, las industrias peligrosas, el abastecimiento de agua, la recogida de basuras, etc. Estaba capacitada para dictar disposiciones para combatir enfermedades transmisibles en los hombres y en los animales, para menguar algunas costumbres dañinas a la salud pública, para eliminar las causas que originaran el paludismo y establecer 
reglas de cuarentena interiores (Delgado, 1996, Valera, 2018).

A la Junta, se le adjudicó, por la Orden No. 159, del 17 de mayo de 1902 , todos los trabajos relativos a la lepra, el muermo, la tuberculosis, la vacuna y la higiene especial. En cada municipalidad se fundó una Junta Local de Sanidad, presidida por los Jefes Locales de Sanidad e integrada por los Oficiales de Cuarentena y los Jefes Locales del, Servicio de Higiene Especial, como vocales (Delgado, 1996; Beldarraín, 2014).

Entre las acciones iniciales de este período estuvo la campaña de higienización de las poblaciones, originada por las condiciones insalubres de la isla como resultado de las acciones bélicas. El Servicio de Inspección Sanitaria de las Casas fue el que primero funcionó en cada ciudad y pueblo, que fueron divididos en distritos, con un médico inspector en cada uno, La Habana quedó dividida en 100 distritos. El cambio en la apariencia de las poblaciones fue un resultado inminente de estas acciones. Se recogió la basura y los animales muertos dispersos en las calles, se trabajó en la obligatoriedad del llenado del informe de enfermedades transmisibles de declaración obligatoria, que se amplió e incluyó un grupo de nuevas dolencias; se tomaron las medidas de desinfección y aislamiento adecuado en cada caso (Beldarraín, 2014; Delgado, 1996).

La creación de la Comisión de la Fiebre Amarilla, por la Orden Civil No. 15, del 7 de agosto de 1899, fue de gran importancia. Esta Comisión tuvo a su cargo el estudio hasta tener un diagnóstico definitivo, de todos los casos comunicados como sospechosos o confirmados de la enfermedad a las oficinas municipales de sanidad. Estuvo presidida en un inicio por el doctor Carlos J. Finlay, el doctor Jorge Le Roy y Cassá como secretario y los doctores Diego Tamayo Figueredo, WiIliam C. Gorgas, Jefe de Sanidad del Ejército Norteamericano en Cuba, Henry Carter, Jefe de Sanidad Marítima y John Davies, Jefe de Sanidad de La Habana, como vocales (Delgado, 1996; Beldarraín, 2014).

La vacunación antivariólica fue elevada a una acción obligatoria, la cual se reglamentó a través de la Orden Militar No. 165, del 24 de junio de 1901. Se integró la Comisión de la Vacuna, formada entonces por el médico norteamericano Valeri Havard y los cubanos doctores Dámaso Lainé Garesche, Juan Guiteras Gener, Vicente La Guardia Maden y Luis Ma. Cowley Valdés-Machado, esta comisión ejecutó una excelente labor.
El 19 de mayo de 1902, terminó el periodo de la intervención norteamericana, para estas fechas se implementaron algunas medidas de importancia en el campo sanitario, como fueron la instalación del agua del Acueducto de Vento en todas las casas y comercios de La Habana; entró en vigor el Reglamento General para el Servicio de Higiene de la Prostitución e Higiene Especial de la Isla; el de ejercicio de la Veterinaria y los reglamentos y leyes de cuarentenas (López Serrano, 1981, Beldarraín, 2014).

\section{LA VIRUELA ENTRE 1899 Y 1902}

En esos años, se mantuvo presente la viruela, la principal medida de lucha contra la enfermedad, continuó siendo la vacunación. La misma evolucionó y ya no era necesario traspasarla de una persona vacunada a la sana, pues se producían en los laboratorios que existían en el país.

Desde 1899, no hubo epidemias de viruela en Cuba. En 1901 - 1902 se realizó una enorme campaña de vacunación, que abarcó casi 266 mil personas, para ello se formó, previamente, en 1901, un centro oficial para la producción y distribución masiva de la vacuna y se estableció su obligatoriedad (Le Roy, 1922, p. 34 - 59).

Como se dijo en párrafos anteriores, desde mediados de 1901, la vacunación era obligatoria en el país.

\section{LA LUCHA CONTRA LA VIRUELA EN LA NUEVA REPÚBLICA}

El 20 de mayo de 1902, surgió la República de Cuba y terminó oficialmente el periodo de la intervención militar del vecino país. La sanidad estaba dirigida por una Junta Nacional de Sanidad, que tenía una subsidiaria en las municipalidades y principales ciudades de la Isla. Esta junta pertenecía a la Secretaría de Gobernación, la cual estaba dirigida por el doctor Diego Tamayo Figueredo, médico ilustre, sensibilizado con los problemas de control sanitario y lucha contra las epidemias. La junta tuvo una relativa independencia, para presidirla Tamayo nombró al médico cubano más importante del momento: al doctor Carlos J. Finlay y Barrés, quién había identificado al agente transmisor de la fiebre amarilla, su mecanismo de transmisión y desarrolló la estrategia para su control, lo que les permitió a las autoridades norteamericanas de la ocupación, eliminar la enfermedad de la isla (López Sánchez, 
1997). Para luchar contra la viruela, la Junta, decidió hacer una estrategia masiva de vacunación en la población (Le Roy,1922; Beldarraín, 2014).

En 1909, el gobierno cubano, decidió establecer una institución de nivel central, con rango ministerial, que se encargara de los asuntos relacionados con la salud pública, así surgió la Secretaría de Sanidad y Beneficencia, la cual fue el primer ministerio de este ramo en el mundo (Delgado, 1996).

\section{El Servicio de Vacunación de URgencia}

Dicha Secretaría, decidió continuar con los trabajos de vacunación que ya se realizaban desde la etapa de la Junta. Un ejemplo de las medidas tomadas contra la enfermedad, fue la Vacunación de Urgencia. Servicio practicado por primera vez, con motivo de la existencia de un caso de viruelas, importado en diciembre de 1909 (Rodríguez, 1910, p. $125-28)$.

Se dispuso que este servicio fuese practicado con toda urgencia, por primera vez, a causa de un caso de viruelas importado. Se comenzó simultáneamente en las cinco zonas que se decidió tenían riesgo de contaminación: la vecindad del Hospital "Las Animas", donde el paciente fue finalmente ingresado; las inmediaciones de la Quinta Covadonga, donde había sido atendido el paciente, antes de ser remitido a "Las Ánimas", los alrededores de la vivienda de la calle Cuba No. 60 y la vecindad de la calle Aguiar No. 29, lugares donde residía y visitaba, además del litoral de los Muelles, de la calle Sol a Jesús María, cuya distribución, abarcando en conjunto un radio notablemente extenso de la población, debía cubrirse con 14 vacunadores que se asignaron.

En la tarde del viernes 19 de diciembre, se dio la orden para la organización y en la mañana siguiente por el día, comenzó a realizarse la vacunación a domicilio, excepto en el litoral de los muelles, en que se indicó expresamente se atendiera solo a las posadas, fondas, cafés, restaurantes y casas de vecindad.

En 10 días hábiles, quedó complementado el servicio, fue terminada el 6 de enero. El número total de vacunados fue, de 7765 personas, de ellos por primera vez, 680 y 6885 revacunados. Lo que resultó una media 776 vacunados por día, 55 por vacunador.
Encontrándose el enfermo en hospital "Las Ánimas", se consideró urgente adelantar el trabajo a esta zona, por lo que fue necesario traer médicos de las inmediaciones, de la Quinta Covadonga, única que podía suministrarlos, sin paralizar del todo su servicio de vacunación.

Terminada la vacunación en las zonas seleccionadas, se decidió, por la Dirección de Sanidad, continuar el servicio, en la parte de la ciudad comprendida desde el litoral de los muelles hasta la calle Aguiar, límite Oeste y como límite Norte y Sur, las calles de Peña Pobre y Desamparados, ejecutando la vacunación vivienda por vivienda, se incluyeron a los empleados de los establecimientos de comercio, oficinas, la totalidad de edificios públicos de la Administración.

Fuera de la zona, se vacunó a todo el personal de los precintos de Policía, así como de los Colegios Públicos y la mayoría de los particulares.

En esta segunda etapa del servicio, se cumplimentó la vacunación en 27 días, obteniendo un grupo de 806 vacunados, 17250 revacunados, que unidos a las cifras anteriores ofrecen un total general 25821 individuos con 14 vacunadores (Rodríguez, 1910, p. $125-28)$.

Esta estrategia de Vacunación de Urgencia, se repitió, cada vez que se diagnosticó un caso de viruela.

La Secretaría de Sanidad, siguió ejecutando su programa de vacunación, aún en los períodos y lugares donde no se presentaron casos de la dolencia.

En la investigación realizada, se encontraron estadísticas de las vacunaciones efectuadas, en los años 1908 - 1909 y 1922 - 1923 (Cuadro No. 3).

Cuadro No. 3. Vacunaciones efectuadas por año. Cuba. $1908-1909$ y $1922-1923$

\begin{tabular}{|c|c|}
\hline Año & Vacunaciones \\
\hline 1908 & 37034 \\
\hline 1909 & 60858 \\
\hline 1922 & 324008 \\
\hline 1923 & 21929 \\
\hline Total & $\mathbf{4 4 3 8 2 9}$ \\
\hline
\end{tabular}

Fuente: Boletines de Sanidad y Beneficencia 1909, 1910, 1923 y 1924.

Hasta 1922, se encontraron registros de un total general de 443829 vacunaciones realizadas. A partir de 
1908 fue aumentando el número de inmunizaciones hasta lograr la mayor cantidad en 1922, con 324008 dosis aplicadas, en los últimos años estuvo en consonancia con las con las intensas labores de los higienistas de la época, por acabar con esta epidemia en Cuba. En 1923, disminuyó esta cifra en concordancia con la erradicación de esta enfermedad en la Isla (Centro General de la Vacuna, 1923, p. 422; Beldarraín, 2018).

\section{ESTRATEGIA FINAL DE CONTROL DE LA VIRUELA}

Contra la viruela, se tomaron enérgicas medidas, a partir de 1915, entre ellas: (Villuendas, 1917, p. 294 - 301) que cuando se presentaba un caso, dondequiera que fuera, se consideraba como un foco epidémico, y así se actuaba. Desde la Dirección de Sanidad, en la capital, se enviaba a uno de sus especialistas, como Comisionado Especial, éste, se hacía cargo de organizar las actividades de control del mismo, casi siempre, de tipo campaña, en conjunto con los especialistas y trabajadores de la jefatura Local de Sanidad. Se enviaban vacunas en cantidad suficiente, para vacunar y revacuanar, a toda la población que se había decidido que estaba en riesgo. Con el concurso de los médicos locales, se organizaba esta vacunación, por ejemplo, en relación a un caso, que se presentó en la región de Santi Spíritus, en enero de 1915, el 18 de dicho mes, se envió a un Comisionado Especial, ya se había organizado la vacunación, por el Jefe Local de Sanidad, junto a dos médicos más, el día 19, ya tenían vacunados en el pueblo de Guayos, a 1100 personas. A partir del día siguiente, continuaron las vacunaciones, hasta agotar la población de 2500 personas.

Las ropas y enseres del paciente, fueron desinfectadas y quemadas. La casa almacén donde trabajaba el enfermo, fue desinfectada, se realizó lavado con solución fuerte de bicloruro, combinada con fumigación con azufre, permanganato y formol. La ambulancia que fue utilizada para trasladar al enfermo, desde Guayos a la ciudad de Santi Spíritus, fue también desinfectada y, además, pintada. Las personas involucradas con la atención del paciente en Guayos, fueron vacunadas y vigiladas. El caso fue confirmado en el hospital, diagnosticado como viruela confluente grave. Se orientó aislamiento absoluto y desinfección intensa. Se organizó una vacunación general en Santi Spíritus, sistematizada con tres médicos, a partir del 21 de enero, cubriendo a unos 4000 habitantes, dividieron la ciudad en tres zonas, a cargo de cada uno, trabajaron casa por casa, inoculando tres horas dia- rias, vacunando cada uno 200 personas semanales, separando la estadística de los vacunados y los revacunados. En Zaza del Medio, poblado vecino de 1500 habitantes, se realizó el trabajo con igual método.

El enfermo, falleció el 20 de enero, se realizaron medidas antisépticas al cadáver y el ataúd fue forrado en el interior de zinc. Se realizó desinfección y fumigación al hospital, cremación de las ropas y almohadas, que utilizó el mismo.

En el Hospital Civil, los médicos estaban cubiertos con batas largas, que cerraban en el cuello y en los puños de las mangas, que eran desinfectadas. Al entrar en la antesala de aislamiento, se cambian de calzado, poniéndose uno de lienzo dispuesto expresamente, se lavan ampliamente las manos con solución fuerte de bicloruro, asistido por un solo enfermero, el cual es inmune a la viruela. Al salir de la visita, se lava nuevamente. El enfermero asistente del enfermo no sale en ningún momento del Departamento. Cada vez que toca al enfermo, se lava las manos con bicloruro. No entra al departamento persona alguna.

El 22 de enero, se quedó preparado el pabellón de aislamiento del Hospital, para asistir a nuevos casos de viruela, si se presentaran (Villuendas, 1917, p. 294 $-301)$.

Se siguió una estricta cuarentena, a los barcos que arribaban al país, con un caso de viruela entre la tripulación o pasajeros, medida, que ayudo al control de la enfermedad y evitar la diseminación de la enfermedad y la aparición de brotes, en el territorio nacional. Por ejemplo, el Centro General de la Vacuna, envió una nota al Director de Sanidad, el 9 junio de 1919, donde refería que a la Isla había llegado un solo caso de viruelas, el 16 de marzo, en el buque inglés Moorgate, surto en Puerto Padre, procedente de Nápoles, con un tripulante afectado de viruela. El buque, se puso a disposición del Departamento de Cuarentenas, fue enviado a la estación de cuarentenas del Mariel, donde dejó al varioloso y fue fumigado convenientemente (Centro General de la Vacuna, 1919, p. $120-143$ ).

El Centro General de la Vacuna, se quejaba, en una nota al Director de Sanidad, el 9 junio de 1919, donde clamaba que a pesar que en Cuba existía vacunación obligatoria, la Ley no se cumplía. Además, apuntaba que, en la Isla, la viruela no era endémica, gracias al buen servicio de la Secretaría de Sanidad, cuyo Departamento de Cuarentenas cumplía siempre su deber, sumado al trabajo de vacunación (Centro General 
de la Vacuna, 1919, p. 120 - 143). Los enfermos que arribaban en los barcos, se aislaban en el Hospital "Las Ánimas" (Centro General de la Vacuna, 1919, p. 120 - 143; Centro General de la Vacuna, 1922, p. 349 $-358)$.

Se realizaron numerosas vacunaciones y revacunaciones en estos años, desde 1915 a 1919 (Centro General de la Vacuna, 1919, p. 120 - 143).

Hay documentados, en 1920, en Cuba, la existencia de 2150 casos de viruela, con 36 defunciones (Boletín de Sanidad y Beneficencia Vol. 26, 1921).

El 5 de agosto de 1921, se emitió un Informe del Centro General de la Vacuna, dirigido al Secretario de Sanidad, que presentaba la estadística de las primeras vacunaciones realizadas por el Centro, en el período de 40 días, comprendidos del 17 de junio, en que se comenzaron las inoculaciones con la vacuna preparada, hasta el 26 de julio, por las cifras, se comprueba la bondad de la vacuna, el éxito alcanzado fue del 94 $\%$. En esa ocasión, los niños vacunados fueron 32; 15 con éxito, 5 negativos y 12 se ignora el resultado.

La vacuna después de preparada y comprobada, daba un conteo de bacterias tan solo de 640 por $\mathrm{cm}^{3}$ y estos banales, haciéndolos sembrar en agar, en placas de Petri en caldo lactosado. En relación a la virulencia del preparado vacunal, la prueba más sólida es el vacunado, pues la vacuna prendía con eficacia.

La vacuna que poseía la Secretaria de Sanidad y Beneficencia, conservada, por medio de transmisiones reguladas en terneras, en lugar ajeno al centro, es, a no dudarlo de buena calidad y virulencia. Las terneras inoculadas han prestado siempre los caracteres de una vacuna verdadera y de potencial virulencia, sin tener que lamentar la infección de una sola ternera y como consecuencia lógica la supuración de sus pústulas.

Se realizaron 64 vacunaciones en el reparto Juanelo, ceca de la capital. Hecha la comprobación el día 2 de julio, se examinaron 52 niños de los vacunados con éxito completo, sin infección de ningún género, presentando las vacunas los caracteres típicos de las mismas y una gran virulencia.

En 1922, el jefe del Servicio de Vacuna, emitió orientaciones sobre la conducta a seguir por los Jefes Locales de Sanidad: (Centro General de la Vacuna, 1922, p. $349-358$ ), estas orientaciones (cuadro No. 4) fueron cumplidas con rigurosidad y obtuvieron un buen resultado, dado que en 1923 y en lo adelante, no se registraron casos de viruela en Cuba.
Cuadro No. 4. Orientaciones impartidas por el Servicio de Vacuna de la Secretaria de Sanidad y Beneficencia en 1922

\begin{tabular}{|c|}
\hline Medidas generales \\
\hline - Llama la atención sobre el carácter de benignidad del \\
brote de ese momento, con fácil diseminación y contagio. \\
Se debe proceder igual que con los casos graves. \\
- Todo caso de viruela constituye un foco de infección y es \\
un peligro por su fácil propagación. \\
- Cuando ocurre un caso de viruela en su demarcación, el \\
Jefe Local de Sanidad dará cuenta por telégrafo, a la \\
Dirección de Sanidad y todos los días participará el \\
movimiento ocurrido en los casos de esta enfermedad. \\
- Prohibición de barrer la habitación del enfermo, ésta se \\
limpiará con un paño mojado en solución desinfectante. \\
Solución de bicloruro al 1 por 1 o00, se usará para lavar \\
las manos de los asistentes del enfermo, esterilizar la \\
ropa, orinales y otros objetos, sin que haya necesidad de \\
destruir por fuego, nada más que las colchonetas y \\
almohadas usadas por el paciente. \\
- Una vez el Alta Sanitaria, se desinfectará el local (con \\
vapores de formaldehido o azufre), lavado de pisos y \\
paredes, o blanqueo de éstas.
\end{tabular}

\section{Vacunación}

- La vacunación debe ser dirigida por el Jefe Local de Sanidad. Hacerse un censo completo de los habitantes de la casa infectada y de las personas que se hayan puesto en contacto con enfermos, con sus direcciones, desde el inicio de los primeros síntomas hasta el diagnóstico, de modo que no escape nadie a la vacunación inmediata, que debe comprender a los residentes, ausentes y posibles contactos.

- A los contactos, debe practicarse cuatro inoculaciones vacunales y vigilar que no se quiten el virus inoculado.

- Los ausentes en el momento de la vacunación, deben asistir a vacunarse en un lugar señalado dentro del plazo de tres días (de carácter obligatorio, Artículo 285 de las Ordenanzas Sanitarias), si no acude, dar cuenta al Juez Correccional, se procede a la celebración del juicio correspondiente, en cuyo acto deberá ser vacunado.

- En los términos municipales de gran extensión, se han designado vacunadores auxiliares, no médicos, pagados, con fondos de la Jefatura Local o con cargo al Fondo de Epidemias.

- En la oficina de la Jefatura Local de Sanidad debe llevarse un libro del registro de las vacunaciones.

\section{Medidas específicas}

- Aislamiento del caso en una sala de hospital o en un lugar adecuado, bastando que no tenga contacto con las casas vecinas.

- Vigilancia estricta, que no entre ni salga persona alguna que no esté inmunizada.

- Evitar posibles infecciones secundarias de la piel, baños generales templados con solución sublimada al 1 por 12 000, diariamente, desde la aparición de las pústulas hasta su curación completa.

- La curación, diagnosticada por el médico de asistencia, no constituye el Alta Sanitaria, no debe darse mientras existan elementos desecados del exantema, que tardan muchos días en caer de las extremidades inferiores.

Fuente: cuadro elaborado por el autor de las Orientaciones impartidas por el jefe del Servicio de Vacuna, sobre la conducta a seguir por los Jefes Locales de Sanidad: (Centro General de la Vacuna, 1922, p. $349-358$ ) 


\section{CONCLUSIONES}

El análisis histórico del desarrollo pormenorizado de la vacunación antivariólica en Cuba, en el periodo comprendido entre los inicios de la práctica vacunal en 1804 y la eliminación de la enfermedad en los inicios de la tercera década del siglo XX, es un ejemplo paradigmático del conjunto de factores de índole científica, social y política que intervienen en un proceso de estas características, con avances y retrocesos, pero que permitieron, como en otros lugares, que la enfermedad pudiera ser contenida en la isla. En el conjunto de acciones y estrategias para hacer frente a la viruela, nos centramos en la vacunación como elemento clave.

Se distinguen cuatro etapas en dicho proceso. La primera, viene marcada por la impronta de la figura de Tomas Romay, quien no escatimó esfuerzos hasta obtener la vacuna y empezar a propagarla y está condicionada por la creación y actividades de la Junta Central de la Vacuna, instauradas aquí como en otros lugares bajo el impulso de la Real Expedición Filantrópica de la Vacuna, la cual dirigió con eficiencia y tesón, logrando llevar el trabajo de la misma y sus subalternas en diferentes pueblos y ciudades, la cual cesó en sus funciones en 1849, con la muerte de su fundador. Una segunda etapa, que abarca la siguiente mitad del siglo XIX, cuando las actividades de vacunación fueron asumidas por la Junta Superior Gubernativa de Medicina y Cirugía, primero y su transformación en Junta Superior de Sanidad después. En este lapso surgieron otros centros de difusión de la vacuna, como fue el caso de la Real Academia de Ciencias Médicas y Naturales de La Habana (desde 1869) y en las Casas de Socorro, surgidas en 1871 , las cuales tenían un servicio de vacunación y utilizaban la propagación de la vacuna brazo a brazo fun- damentalmente, aunque en algunas ocasiones la linfa vacunal fue importada del extranjero. En este período inició sus actividades el Instituto de Vacunación Animal, como centro de producción de vacuna.

En 1880, se inauguró en la Sociedad Económica de Amigos del País, el centro "Tomás Romay", para proveer servicios de vacunación a la población y las autoridades coloniales crearon en 1890, de un centro público para la producción y propagación de la vacuna.

La tercera etapa, corresponde a las actividades antivariólicas realizadas en la época de la intervención norteamericana, donde lo fundamental fue la disposición legal que hizo obligatoria la vacunación.

La cuarta y última etapa se corresponde a la lucha contra la enfermedad en los primeros años de la República, dese 1902. Las actividades de vacunación estuvieron en un principio bajo la jurisdicción de las Juntas de Sanidad, ya fuera la Nacional o las Jefaturas Locales de Sanidad. A partir de 1909, estas actividades fueron dirigidas por la Secretaría de Sanidad y Beneficencia recién creada, con un Servicio de Vacuna y dentro de éste se destacó el Servicio de Vacunación de Urgencia, con una rigurosa labor que tuvo su impacto positivo en el aumento del nivel inmunitario de la población expuesta al riesgo ante los brotes epidémicos presentados en esos momentos o ante un caso aislado de la enfermedad. También funcionó el Centro de la Vacuna, el cual se encargó de la producción de la misma y su distribución, así como la formación y entrenamiento de miles de vacunadores en este período. En esta etapa y fruto de la estrategia de trabajo de las instituciones presentadas se eliminó la viruela, cuyos últimos casos se presentaron en 1922. 


\section{NOTAS}

1 La Real Sociedad Económica de Amigos del País, se fundó en Santiago de Cuba en 1787 y en La Habana, en 1793, ésta última, estuvo presidida en sus días inaugurales por el capitán general D. Luis de las Casas, fue un miembro influyente el Obispo capitalino D. Juan José Díaz de Espada y Fernández de Landa. Apoyó todas las medidas sanitarias de su época, e impulsó el desarrollo de las ciencias -en general- de la Isla y de la medicina -en particular-. Esta institución encarnó el afán de progreso de la nueva clase social, enriquecida con la producción y el comercio del azúcar. Estuvo compuesta por intelectuales, hacendados y comerciantes. Trató incrementar el crecimiento económico de la Isla y de mejorar la calidad de vida de los ciudadanos, abrió escuelas y tuvo la primera biblioteca pública. Fue conocida también como Real Sociedad Patriótica o Sociedad Patriótica, al finalizar la dominación española, se conoció como Sociedad Económica de Amigos del País (Abascal, 1941).

\section{BIBLIOGRAFÍA}

Abascal, Horacio (1941), Contribución de la Sociedad Económica al progreso de la medicina en Cuba. (Discurso leído en la Sociedad Económica de Amigos del País, 9 de enero de 1941). La Habana, Molina y Cía.

Anales de la Real Academia de Ciencias Médicas, Físicas y Naturales de La Habana (1869), 7, pp.171.

Anales de la Real Academia de Ciencias Médicas, Físicas y Naturales de La Habana (1877), 13, pp. 594.

Anales de la Real Academia de Ciencias Médicas, Físicas y Naturales de La Habana (1878), 14, pp. 533.

Anales de la Real Academia de Ciencias Médicas, Físicas y Naturales de La Habana (1880), 17, pp. 23.

Anales de la Real Academia de Ciencias Médicas, Físicas y Naturales de La Habana (1881), 17, pp. 418.

Anales de la Real Academia de Ciencias Médicas, Físicas y Naturales de La Habana (1881), 17, pp. 506 - 08.

Anales de la Real Academia de Ciencias Médicas, Físicas y $\mathrm{Na}$ turales de La Habana (1888), 24, pp. 579.

Anales de la Real Academia de Ciencias Médicas, Físicas y Naturales de La Habana (1888), 25, pp. 31, 33.

Archivo de la Sociedad Económica, Legajo No. 5, Apéndice E.

Beldarraín Chaple, Enrique (2010), Las epidemias y su enfrentamiento en Cuba 1800 - 1860. Tesis para optar por el grado de Doctor en Ciencias de la Salud, la Habana.

Beldarraín Chaple, Enrique (2014), Las instituciones y la salud pública en Cuba en la primera mitad del siglo XX. Diálogos. Revista electrónica de historia. Escuela de Historia. Universidad de Costa Rica. [citado 27 may 2017]; 15(1): [aprox 16 p.]. Disponible en: http://revistas.ucr.ac.cr/index.php/dialogos/index.

Beldarraín Chaple, Enrique (2018), La situación higiénico-epidemiológica en Cuba durante la época de Juan Guiteras.
2 No disponemos de datos exactos sobre quién y en qué momento se introdujo en Cuba la inoculación, pero era conocida en 1795, pues en el Papel Periódico de La Havana, apareció un cuestionamiento sobre la eficacia e inocuidad del método, que respondió Romay, lo que demostró que conocía el tema. En este artículo, publicado en dos partes, el 29 de octubre y el 19 de noviembre, del mismo año, se presentó como partidario de la inoculación, recomendó el procedimiento, que consistía en introducir la punta de una lanceta en el pus de las viruelas, hacer con ella una picadura y levantar horizontalmente la epidermis, algo más de una línea, de la persona sana. Pero agregó esta observación: "siempre que no se penetre en la membrana adiposa, pues entonces se sobrevendrán accidentes tales como abscesos y úlceras (López Sánchez, 2004, p. 81).

Revista Cubana de Salud Pública, Vol. 44, No. 2. Disponible en: http://www.revsaludpublica.sld.cu/index.php/spu/rt/ printerFriendly/958/1032

Centro General de la Vacuna (1919), Informe del Centro General de la Vacuna, Boletín de Sanidad y Beneficencia, XXII, pp. $120-143$.

Centro General de la Vacuna (1919), Informe del Centro General de la Vacuna, Boletín de Sanidad y Beneficencia, XXII, pp. $120-176$

Centro General de la Vacuna (1921), Informe del Centro General de la Vacuna, Boletín Sanidad y Beneficencia, 26, pp. 145 -149 .

Centro General de la Vacuna (1922), Informe del Centro General de la Vacuna, Boletín de Sanidad y Beneficencia, 27, pp. $349-358$

Centro General de la Vacuna (1923), Servicio de Vacunación, Boletín de Sanidad y Beneficencia, 28, pp. 422.

Cueto, Marcos; Palmer, Steven (2014), Medicine and Public Health in Latinamerica. A history new approaches to the Americas). Cambridge, Cambridge University Press.

Delgado, Gregorio (1987), Historia de la erradicación de algunas enfermedades epidémicas en Cuba. Cuadernos de Historia de la Salud Pública Cubana, 72, pp. $64-5$.

Delgado, Gregorio (1996), Conferencias de historia de la administración de Salud Pública en Cuba. Cuadernos de Historia de la Salud Pública Cubana, 81.

Ely, Roland T. (2001), Cuando reinaba su majestad el azúcar. La Habana, Imagen Contemporánea.

Funes Monzote, Reinaldo (2005), Despertar del asociacionismo científico en Cuba, 1876 - 1920. Centro de Investigación y Desarrollo de la Cultura Juan Marinello, La Habana.

Hernández, Pedro (1802), Origen y descubrimiento de la Vaccina, traducido del francés con arreglo a las últimas obser- 
vaciones hechas hasta el mes de mayo de 1801, y enriquecido con varias notas. Madrid: Benito García.

Le Roy y Cassá, Jorge (1913), Estudios sobre la mortalidad en La Habana durante el siglo XIX y comienzos del actual. La Habana: Imprenta Lloredo.

Le Roy y Cassá, Jorge (1922), Desenvolvimiento de la sanidad en Cuba durante los últimos 50 años (1871-1920). La Habana: Imprenta La Moderna Poesía.

Libro de Acuerdos de la Sociedad Económica, Libro II, folio 458: 55.

Libro de Acuerdos Sociedad Económica, Libro III, folios 133 y 136: 60.

López Espinosa, José Antonio. (2004), El doctor Vicente Luis Ferrer y la revista El Propagador de la Vacuna. ACIMED, 12(1) Recuperado en 26 de julio de 2019, disponible en: http:// scielo.sld.cu/scielo.php?script=sci_arttext\&pid=S102494352004000100008\&lng=es\&tlng=es.

López Sánchez, José (1970), La Medicina en La Habana, Cuadernos de Historia de la Salud Pública Cubana, 47.

López Sánchez, José (1997), Cuba: medicina y civilización, siglos XVII y XVIII, La Habana, Ed. Científico- Técnica.

López Sánchez, José (2004), Vida y obra del sabio médico habanero Tomás Romay Chacón. La Habana, Editorial Científico Técnica.

López Sánchez, José (2016), bicentenario del año de la eclosión científica en cuba (1797 - 1997) en: Excelentísimo Ayuntamiento de Dos Hermanas. José López Sánchez, José Antonio López Espinosa... Y Dos hermanas. Dos Hermanas: Excelentísimo Ayuntamiento de Dos hermanas. Pp 35 - 46. (Miscelanea Oripense; 5).

López Serrano, Elena (1981), La Salud pública en Cuba (18991925). Rev cubana Adm Salud, 7(4): 487-92.

Martínez-Fortún, José Andrés (1952), Epidemiología, síntesis cronológica, Cuadernos de Historia de la Salud Pública Cubana, 5 , pp. $37-51$.

Moreno Fraginals, Manuel (1986), El Ingenio. La Habana, Ciencias Sociales.

Pérez de la Riva, Juan (1972), Desaparición de la población indígena cubana. Revista Universidad de La Habana, 196, pp. 61-84
Pezuela, Jacobo (1868), Historia de la Isla de Cuba. Madrid, Carlos Bailly-Balliere, Tomo 1, pp.112.

Pruna, Pedro (2002), La Real Academia de Ciencias de La Habana, 1861 - 1898, Madrid, Consejo Superior de Investigaciones Científicas.

Ramírez Martin, Susana María (2002a), Por la salud del Imperio. La Real Expedición filantrópica de la Vacuna. Madrid, Doce Calles.

Ramírez Martin, Susana María (2002b), Proyección científica de la ideas de Tomás Romay sobre la vacuna de la viruela en la Inclusa madrileña. Asclepio 54, 109-128.

Real Academia de Ciencias Médicas, Físicas y Naturales de La Habana (1882), Sesión pública del 23 de octubre de 1881, Anales de la Real Academia de ciencias Médicas, Físicas y Naturales de La Habana, 18, pp. 277-79.

Rodríguez, Felipe. (1910), Vacunación de Urgencia. Servicio practicado con motivo del caso de viruelas importado en diciembre último. Sanidad y Beneficencia. Ene- Jun; III : p. 125-128.

Romay Chacón, Tomás (1797), Hemos utilizado la edición de 1965., Disertación sobre la fiebre maligna llamada vulgarmente vómito negro y enfermedad epidémica de las Indias Occidentales. En: Obras Completas. Compiladas por López Sánchez, José, La Habana, Academia de Ciencias de Cuba, Museo Histórico de las Ciencias Médicas "Carlos J. Finlay", Tomo 1, pp- 65 - 84.

Valera Jorge, José Antonio (2018), Las epidemias en Cuba y su enfrentamiento en el período 1902 - 1958. Convención Cuba Salud 2018. La Habana. Disponible en: http://www. convencionsalud2018.sld.cu/index.php/connvencionsalud/2018/paper/download/300/1030.

Villuendas, Florencio (1917), Campaña sanitaria contra la viruela en Guayos, Cabaiguán y Santi Spíritus y en la Villa de Colón. Boletín de Sanidad y Beneficencia, XVIII, pp. 294 $-301$.

Zayas, Joaquín de (1881), Ventajas del ácido salicílico en la viruela, Anales de la Real Academia de Ciencias Médicas, físicas y Naturales de La Habana, 17, pp. 418. 